\title{
Perceived Family and School Rejection and Adolescents' Psychological States
}

\author{
Marwan Dwairy \\ Oranim Academic College, Israel. \\ Email: psy@marwandwairy.com \\ Received May $4^{\text {th }}$, 2011; revised July 11 ${ }^{\text {th }}, 2011$; accepted August 21 $1^{\text {st }}, 2011$.
}

\begin{abstract}
This study deals with the perceived acceptance-rejection of male and female adolescents at home and at school and their association with the psychological states experienced by them. A sample of 350 female and 220 male $10^{\text {th }}$ grade students filled out two questionnaires: Dwairy's Rejection Scale, measuring acceptance-rejection by fathers, mothers, brothers, sisters, male teachers, female teachers, male classmates and female classmates, and the Psychological State Scale, measuring anxiety, depression, psychosomatic symptoms and conduct disorders. The results show that all perceived acceptance-rejection circuits are associated with and merged in three major factors of rejection: family, teachers, and classmates. All the factors were associated with psychological states experienced by the adolescents with a cross-gender effect. Experienced psychological states of male adolescents were associated with perceived acceptance-rejection circuits at home and at school, in particular when related to female figures, while psychological states of female adolescents were associated with male and female figures at home. The results highlight the need for a systemic approach in research.
\end{abstract}

Keywords: Acceptance, Rejection, Parenting, Psychological States, Adjustment

In the middle of the 20th century, in his humanistic theory, Carl Rogers had emphasized the central role acceptance plays in mental health (Rogers, 1951, 1961). He coined the term 'unconditional positive regard' as a vital component of education and counseling, so as to indicate the need of the child to be accepted unconditionally by her family and others, and of the client to be accepted by the counselor. According to Rogers, psychological disorders are rooted in rejection. Ronald Rohner in his acceptance-rejection theory followed in his footsteps and provided empirical evidence of the association between parental acceptance-rejection and children's psychological adjustment. After hundreds of studies inspired by his theory he concludes:

"Children everywhere need a specific form of positive response-acceptance by parents and other attachment figures. When this need is not met satisfactorily, children worldwideregardless of variations in culture, gender, age, ethnicity, or other defining conditions-tend to describe themselves as hostile and aggressive; dependent or defensively independent; impaired in self-esteem and self-adequacy; emotionally unresponsive; emotionally unstable; and to have a negative worldview, among other responses" (Rohner, Khaleque, and Cournoyer, 2005, p. 1).

In the wake of robust evidence regarding the relationship between parental rejection and psychological maladjustment of children, an International Society for Interpersonal Acceptance and Rejection was founded in 2006 at a congress dealing with that issue, organized in Istanbul, Turkey. The society broadened the scope of interest in the field and marshaled support to encourage research related to issues of interpersonal acceptance and rejection, including but not limited to acceptance and rejection by parents, siblings, peers, teachers, spouses, and the entire domain of interpersonal adult acceptance-rejection throughout the lifespan (See volume 1, issue 1 of Interpersonal Acceptance,

*This research was supported by the MOFET Institution (Research, Curriculum \& Program Development for Teacher Educators) and The Research Authority, Oranim Academic College, Israel.
March, 2007).

As for children and adolescents, the two major sources of rejection are the family and school. The significance of their impact was recently studied in a special issue of Cross-Cultural Research (Vol. 44, \#3, 2010), dealing with “Teachers' acceptance, parental acceptance, and the adjustment, achievement, and behavior of school-going youth". It became clear that parental and teachers' acceptance was significantly correlated with the psychological adjustment of both boys and girls (Rohner, 2010; Tulviste, and Rohner, 2010). Some of the studies, reported in the special issue, found a cross-gender effect, for example that fathers have a greater influence on the behavior of their daughters than on that of their sons (Rohner, personal communication, August 13, 2010). In Estonia, only mothers make a significant and independent contribution to boys' adjustment, while fathers have no such influence (Tulviste \& Rohner, 2010). It is still not clear why cross-gender effects such as these sometimes occur, but are not evident in other environments.

In addition to parents and teachers, classmates and siblings play an important role in adolescents' psychological adjustment. In his book Ladd (2005) gathered research findings, indicating that poor relations with classmates are one of the best predictors of multiple forms of psychological, scholastic and interpersonal dysfunctions in childhood, adolescence and adulthood. Children rejected by their classmates tend to display more aggressive behavior (Coie, and Kupersmidt, 1983), and shyness, social withdrawal, poor communication skills, hyperactivity (Ladd, 2005), and absenteeism and dropping out of school (Buhs, Ladd, \& Herald, 2006). When peer rejection is more persistent, the psychological impairment is more severe (Ladd, 2006).

As for siblings, they spend much time together (Walters, 1987), and often serve as confidants or role models to each other (Pulakos, 1987). This relationship contributes a great deal to the psychological development and adjustment of siblings (Hetherington \& Clingempeel, 1992; Rohner, Varan, Kober- 
stein, and Özyavru, submitted), and provides a basis for the understanding of emotions, management of anger, attitudes, and other social skills (Brody, 2004). Sibling relationships involving negative feelings and conflicts may contribute to aggressive behavior (Bank, Patterson, \& Reid, 1996).

Acceptance-rejection by parents is highly correlated with that of teachers (Rohner, 2010), and that of siblings (Rohner, Varan, Koberstein, and Özyavru, submitted). Acceptance-rejection by parents, siblings, teachers and classmates seems to be associated and they impact the child's behavior. These circuits are continuous, dynamic, multi-directional, and related to the quality and characteristics of each of the parties. Therefore, and consistently with my systemic research approach (Dwairy, 2006, 2009a, 2009b), it is crucial to study these associations together. A few studies have explored the relationship between these circuits, such as the impact of teachers and parents (Rohner, 2010, Tulviste, and Rohner, 2010) or parents and siblings (Rohner, et al. submitted). Some studies have shown that parents and teachers are intermediate: In Bangladesh, for instance, both teacher and parental acceptance were significantly correlated with students' psychological adjustment; however, results of multiple regressions revealed that only teachers' acceptance (but not parental acceptance) made a significant and independent contribution to variations in the adolescents' (both males' and females') psychological adjustment (Rohner, Khaleque, Elias, and Sultan, 2010). Interestingly, as far as we know, no research has been carried out on the acceptance-rejection by parents, siblings, teachers, and classmates all combined, and on the associations between these circuits and the children's psychological adjustments. This systemic research approach is crucial, because circuits of rejection constitute one whole system.

The association between acceptance-rejection and psychological disorders depends on how the rejecting act is perceived. In some cultures, for instance, authoritarian parenting, parental control, and punishments are perceived positively and associated with care and love (Chao, 1994, 2001; Dwairy, Achoui, Farah, \& Abouserie, 2006; Rohner and Pettengill 1985). Therefore, in this research we focus on the perceived acceptancerejection and the experienced psychological states of adolescents as it is expressed through self-report measures. Because the association between acceptance-rejection and psychological adjustment of children is gender specific (Rohner, 2010), in this research we studied the acceptance-rejection circuit in a gender specific manner. The association between male and female adolescents' psychological adjustment and eight circuits of rejection (those of mother, father, sisters, brothers, female and male teachers, and female and male classmates) were studied together. We hypothesized that all rejection phenomena are associated and that all of them are associated with the adolescents' psychological adjustment. In addition, we hypothesized to find a cross-gender effect on adolescents' psychological states: The associations between adolescents' psychological adjustment and rejection would be significant when the rejection would come from an opposite-sex parent, siblings, teachers, or peers.

\section{Methods}

\section{Samples}

The sample consisted of 350 female and 220 male 10th grade students (15 - 16 years old) in five villages in northern Israel.
Based on the demographic data they provided, $37.2 \%$ of the fathers and $27.2 \%$ of the mothers had less than 12 years of education. About a third of the parents had finished high school and $31.5 \%$ of the fathers and $40.3 \%$ of the mothers had completed higher education at a college or university. About 54\% of the subjects reported that the family's economic level was within the average range of the population. Only 5.9\% reported an economic level below the average and $40.1 \%$ above the average.

\section{Procedures}

Questionnaires with standard instructions were administered by M.A. students of educational counseling. The high school students had 40 minutes to fill out the questionnaires during an education course. In accordance with the school regulations, consent was obtained from the school inspector and/or the parents' committee. Participation was voluntary; however, there were no refusals.

\section{Instruments}

In addition to the demographic information, the subjects were asked to fill out two questionnaires: Dwairy's Rejection Scale and Psychological State Scale.

Dwairy's Rejection Scale: Until then parental acceptancerejection had been measured mainly by means of questionnaires, and peer rejection via sociometric rating and nomination methods, teacher reports, and observations (Ladd, Herald, Slutzky, \& Andrews, 2004; Nelson, Rubin, \& Fox, 2005; Rohner, Khaleque, and Cournoyer, 2005). In order to use one measurement for all circuits of acceptance-rejection, we developed a unified questionnaire that is based on PARTheory. According to that theory, parents express their acceptance or rejection in four main ways, namely by being warm and affectionate, hostile and aggressive, indifferent and neglectful, and an undifferentiated way of rejection. Based on this, 20 items were created to assess these ways. Ten items express acceptance (e.g. This person admires me) and another 10 items express rejection (e.g. This person belittles me). Five psychologists who are familiar with PARTheory were asked to classify these items into two categories: acceptance and rejection. Items that did not obtain full agreement by all the five psychologists were omitted. The final set of items included 12 items: six expressing acceptance and six expressing rejection. This set of items was used to assess acceptance and rejection by eight significant others, as perceived by the adolescent, namely father, mother, brothers, sisters, male teachers, female teachers, male and female classmates. The whole acceptance-rejection scale includes 96 items with 12 parallel items for each significant other. The adolescents are asked to rate their response on a 6-point Likert scale (ranging from $5=$ always, to $0=$ never).

Eight principal factor analysis were conducted on the 12 items concerning each significant other/others acceptance-rejection responses with varimax rotation, a priori two factors solution, and a .20 loading criterion. In all eight analyses all items of acceptance were loaded in one factor and all items of rejection were loaded in the second factor. The explained variances varied from $47.5 \%$ to $66.7 \%$ (Table 1). The scores of the rejection items were reversed. Alpha Chronbach's coefficient for the father, mother, brothers, sisters, male teachers, female teachers, male classmates, and female classmates was calculated and found $.85, .87, .91, .91, .87, .86, .87$, and .90 respectively. The mean of the reversed six rejection items was added to the mean of the six acceptance ones to obtain a score of ac- 
Table 1.

Principal factor analyses of the twelve items of acceptance-rejection for each significant figure/s.

\begin{tabular}{|c|c|c|c|c|c|c|c|c|c|c|c|c|c|c|c|c|}
\hline \multirow{2}{*}{$\frac{\text { Item }}{\text { Listen with interest to what I am saying }}$} & \multicolumn{2}{|c|}{ Father } & \multicolumn{2}{|c|}{ Mother } & \multicolumn{2}{|c|}{ Brothers } & \multicolumn{2}{|c|}{ Sisters } & \multicolumn{2}{|c|}{$\begin{array}{c}\text { Male } \\
\text { Teachers }\end{array}$} & \multicolumn{2}{|c|}{$\begin{array}{l}\text { Female } \\
\text { Teachers }\end{array}$} & \multicolumn{2}{|c|}{$\begin{array}{c}\text { Male } \\
\text { Classmates }\end{array}$} & \multicolumn{2}{|c|}{$\begin{array}{c}\text { Female } \\
\text { Classmates }\end{array}$} \\
\hline & .75 & & .65 & -.37 & .76 & -.21 & .73 & -.27 & .69 & -.26 & .71 & -.26 & .71 & -.22 & .75 & -.24 \\
\hline Does not pay attention to what I am saying & -.23 & .52 & -.26 & .60 & -.32 & .67 & -.26 & .75 & -.28 & .57 & & .72 & -.41 & .44 & -.36 & .60 \\
\hline Praise me in front people & .57 & & .70 & & .77 & & .75 & & .75 & & .79 & & .78 & & .85 & \\
\hline Insult me in front people & -.30 & .61 & -.34 & .58 & -.24 & .76 & -.21 & .79 & & .73 & & .75 & & .77 & -.21 & .77 \\
\hline Admires me & .68 & -.35 & .78 & -.21 & .79 & -.24 & .80 & -.21 & .73 & & .81 & & .86 & & .83 & -.25 \\
\hline Belittles me & -.21 & .69 & & .69 & -.23 & .80 & -.23 & .85 & -.21 & .73 & & .73 & -.40 & .66 & -.34 & .75 \\
\hline Helps me when I need help & .62 & -.26 & .72 & -.26 & .79 & -.25 & .83 & -.22 & .76 & -.29 & .75 & -.25 & .84 & & .85 & -.23 \\
\hline Does not care to my needs and difficulties & & .68 & & .64 & -.31 & .78 & -.22 & .79 & -.25 & .64 & -.36 & .49 & -.28 & .60 & -.30 & .71 \\
\hline Understands my weakness and difficulties & .71 & & .70 & -.30 & .80 & -.25 & .85 & -.27 & .77 & & .75 & & .77 & -.20 & .82 & \\
\hline Stresses me in his request and expectations & -.24 & .57 & & .56 & & .72 & & .68 & & .64 & & .45 & & .51 & & .68 \\
\hline Cares for my feelings & .77 & -.22 & .68 & -.40 & .77 & -.36 & .78 & -.30 & .77 & -.21 & .73 & -.28 & .73 & -.23 & .79 & -.23 \\
\hline Indifferent toward my feelings & -.48 & .45 & & .69 & -.40 & .71 & & .81 & -.44 & .55 & -.38 & .58 & & .74 & & .81 \\
\hline Explained variance & 27.4 & 20.1 & 27.4 & 23.9 & 34.4 & 30.6 & 33.5 & 33.2 & 31.2 & 23.2 & 31.6 & 22.0 & 34.6 & 21.3 & 36.7 & 28.2 \\
\hline
\end{tabular}

ceptance of each figure. A higher score indicates a higher acceptance.

The Psychological State Scale: The items of this scale were taken from a broader scale, developed in Arabic by Hamuda and Imam (1996) to assess twenty-seven psychological states among adolescents and adults in Egypt. In our scale we included items that assess the most common four psychological states: anxiety (e.g. I feel anxious, I am worried), depression (I feel sad, I don't feel like doing anything), conduct disorder (I respond violently, I disobey rules), and somatization (I feel fatigue, I feel pressure in my chest). Our scale included 20 items (five for each state) and the adolescents were asked to rate their response on a 6-point Likert scale (ranging from $5=$ always, to $0=$ never). Alpha Cronbach's coefficient of the scale was .95 , indicating a robust internal homogeneity (Dwairy, Achoui, Filus, Rezvan nia, Casullo, \& Vohra, 2010). The sum of the scores on this scale serves us to assess the psychological states among adolescents.

\section{Results}

We calculated the means of the perceived acceptance-rejection scores of male and female adolescents. Table 2 shows that female adolescents reported more acceptance by fathers, female classmates, and male and female teachers than male adolescents did. Moreover, the attitude of sisters to their brothers and sisters was more accepting than that of brothers. The scores of experienced psychological states among female adolescents were significantly higher than those among male adolescents. A post hoc analysis indicated that female adolescents experience higher anxiety, depression and somatic symptoms than male adolescents, but not conduct problems.

To understand the relationship between the eight perceived acceptance-rejection circuits with the eight significant other/s, Pearson's correlations coefficients were calculated (Table 3) and they indicated significant shared variances between the acceptance-rejection scores of all circuits. The shared variance was especially high between male and female parents, siblings, teachers, and classmates. Table 3 also shows the correlation coefficients between the perceived acceptance-rejection circuits and psychological states experienced by adolescents and indicates that all the circuits are associated with psychological states: The higher the acceptance, the lower the psychological states.

Because of the high correlation coefficients between acceptance scores of all eight circuits, we conducted series of principal factor analyses on all items of acceptance-rejection (96 items) with a priori 8 then 4 factors solution and varimax rotation. We found that the items of parents and siblings tend to merge in the same factor, therefore we conducted factor analyses on all items with a priori 3 factors and found that factor one explained $12.5 \%$ of the variance and included all items of father, mother, brothers, and sisters, and we labeled it Family's Acceptance. Factor two explained $10.27 \%$ of the variance and included all items of the male and female classmates, and we labeled it Classmates' Acceptance, and factor three explained $8.98 \%$ of the variance and included all items of male and female teachers and we labeled it Teachers' Acceptance.

Multiple regression was conducted to learn about the associations between these three factors of acceptance and psychological states of male and female adolescents, and we found that all of them were significantly associated among male and female adolescents (Table 4). The acceptance-rejection factors explain $22 \%$ of the male and $20 \%$ of the female psychological states.

In order to learn more specifically about the contribution of each acceptance-rejection circuit to explaining psychological states' variance, we conducted a post hoc stepwise regression on the eight circuits among males and females. The model that explains the male psychological states included perceived acceptance-rejection of mother, sisters, female teachers, and male classmates, with $\mathrm{R}^{2}=22.4$. The model that explains the female psychological states included perceived acceptance-rejection by 
Table 2 .

Means of acceptance-rejection and psychological states among male and female adolescents.

\begin{tabular}{|c|c|c|c|c|c|c|}
\hline & & $\mathrm{N}$ & Mean & S. D & F & Sig. \\
\hline \multirow{3}{*}{ Father AcRj } & male & 217 & 7.86 & 1.47 & \multirow{3}{*}{9.12} & \multirow{3}{*}{.003} \\
\hline & female & 321 & 8.28 & 1.40 & & \\
\hline & Total & 538 & 8.08 & 1.44 & & \\
\hline \multirow{3}{*}{ Mother AcRj } & male & 217 & 8.33 & 1.35 & \multirow{3}{*}{ n.s } & \multirow{3}{*}{ n.s } \\
\hline & female & 321 & 8.49 & 1.48 & & \\
\hline & Total & 538 & 8.42 & 1.43 & & \\
\hline \multirow{3}{*}{ Brothers AcRj } & male & 217 & 7.80 & 1.55 & \multirow{3}{*}{ n.s } & \multirow{3}{*}{ n.s } \\
\hline & female & 321 & 7.78 & 1.92 & & \\
\hline & Total & 538 & 7.79 & 1.78 & & \\
\hline \multirow{3}{*}{ Sisters AcRj } & male & 217 & 8.34 & 1.32 & \multirow{3}{*}{ n.s } & \multirow{3}{*}{ n.s } \\
\hline & female & 321 & 8.48 & 1.55 & & \\
\hline & Total & 538 & 8.42 & 1.46 & & \\
\hline \multirow{3}{*}{ Male teachers AcRj } & male & 217 & 6.77 & 1.98 & \multirow{3}{*}{14.76} & \multirow{3}{*}{.000} \\
\hline & female & 321 & 7.35 & 1.54 & & \\
\hline & Total & 538 & 7.12 & 1.75 & & \\
\hline \multirow{3}{*}{ Female teachers AcRj } & male & 217 & 7.22 & 1.68 & \multirow{3}{*}{14.83} & \multirow{3}{*}{.000} \\
\hline & female & 321 & 7.76 & 1.54 & & \\
\hline & Total & 538 & 7.54 & 1.62 & & \\
\hline \multirow{3}{*}{ Male classmates AcRj } & male & 217 & 7.93 & 1.51 & \multirow{3}{*}{ n.s } & \multirow{3}{*}{ n.s } \\
\hline & female & 321 & 7.97 & 1.47 & & \\
\hline & Total & 538 & 7.95 & 1.49 & & \\
\hline \multirow{3}{*}{ Female classmates AcRj } & male & 217 & 7.87 & 1.71 & \multirow{3}{*}{37.04} & \multirow{3}{*}{.000} \\
\hline & female & 321 & 8.69 & 1.41 & & \\
\hline & Total & 538 & 8.36 & 1.59 & & \\
\hline \multirow{3}{*}{ Psy. Disorders } & male & 217 & 22.09 & 15.56 & \multirow{3}{*}{16.37} & \multirow{3}{*}{.000} \\
\hline & female & 321 & 28.78 & 20.75 & & \\
\hline & Total & 538 & 26.08 & 19.10 & & \\
\hline
\end{tabular}

mother, father, and brothers, with $\mathrm{R}^{2}=21.9$ (Table 5). In this analysis we notice that some associations between perceived acceptance-rejection circuits and experienced psychological states that were significant when treated separately as was shown in Table 3, became insignificant because of the shared variance between the acceptance-rejection circuits.

\section{Discussion}

This study explored the associations between eight perceived acceptance-rejection circuits and experienced psychological states by male and female adolescents. We found that female adolescents display and receive more acceptance than male adolescents, and yet, apparently also for other reasons they experience higher anxiety, depression, and somatic symptoms.

In accordance with our hypothesis, the eight circuits of perceived acceptance-rejection were associated. The shared variance was especially high between male and female parents, siblings, teachers, and classmates. This may indicate a general perceived atmosphere of acceptance-rejection that all significant others share in their attitude to the adolescent. This shared acceptance-rejection may be attributed to mutual influences between the figures (e.g. father and mother or male teachers and female teachers), but such influences could barely occur among some figures that were also correlated, such as parents and classmates. Therefore it appears that the shared acceptance-rejection tendencies may also be attributed to the adolescents' characteristics or behavior that may evoke certain levels of acceptance-rejection. Alternatively, it may be attributed to a 
Table 3.

Correlation coefficients between acceptance factors and psychological states.

\begin{tabular}{|c|c|c|c|c|c|c|c|c|c|}
\hline Acceptance by & Fath. & Moth. & Broth. & Sist. & M. teach. & F. teach. & M.clssmts & F. clssmts & $\mathrm{Pd}$ \\
\hline Father & 1.00 & $.56^{* *}$ & $.43^{* *}$ & $.35^{* *}$ & $.30^{* *}$ & $.35^{* *}$ & $.35^{* *}$ & $.42^{* *}$ & $-.34^{* *}$ \\
\hline Mother & $.56^{* *}$ & 1.00 & $.48^{* *}$ & $.46^{* *}$ & $.31^{* *}$ & $.30^{* *}$ & $.36^{* *}$ & $.32^{* *}$ & $-.38^{* *}$ \\
\hline Brothers & $.43^{* *}$ & $.48^{* *}$ & 1.00 & $.49^{* *}$ & $.20^{* *}$ & $.27^{* *}$ & $.28^{* *}$ & $.37^{* *}$ & $-.32^{* *}$ \\
\hline Sisters & $.35^{* *}$ & $.46^{* *}$ & $.49^{* *}$ & 1.00 & $.26^{* *}$ & $.33^{* *}$ & $.32^{* *}$ & $.34^{* *}$ & $-.25^{* *}$ \\
\hline Male teachers & $.30^{* *}$ & $.31^{* *}$ & $.20^{* *}$ & $.26^{* *}$ & 1.00 & $.75^{* *}$ & $.26^{* *}$ & $.25^{* *}$ & $-.18^{* * *}$ \\
\hline Female teachers & $.35^{* *}$ & $.30^{* *}$ & $.27^{* *}$ & $.33^{* *}$ & $.75^{* *}$ & 1.00 & $.34^{* *}$ & $.36^{* *}$ & $-.16^{* *}$ \\
\hline Male classmates & $.35^{* *}$ & $.36^{* *}$ & $.28^{* *}$ & $.32^{* *}$ & $.27^{* *}$ & $.34^{* *}$ & 1.00 & $.68^{* *}$ & $-.22^{* *}$ \\
\hline Female classmates & $.42^{* *}$ & $.32^{* *}$ & $.37^{* *}$ & $.34^{* *}$ & $.25^{* *}$ & $.36^{* *}$ & $.68^{* * *}$ & 1.00 & $-.19^{* *}$ \\
\hline Psychological states & $-.34^{* * *}$ & $-.38^{* * *}$ & $-.32^{* *}$ & $-.25^{* *}$ & $-.18^{* * *}$ & $-.16^{* * *}$ & $-.22^{* *}$ & $-.19^{* * *}$ & 1.00 \\
\hline
\end{tabular}

${ }^{* *}$ Correlation is significant at the 0.0001 level (2-tailed).

Table 4.

Associations between acceptance factors and psychological states of male and female adolescents.

\begin{tabular}{|c|c|c|c|c|c|c|}
\hline \multirow{2}{*}{ Acceptance factors } & \multicolumn{3}{|c|}{ Male adolescents } & \multicolumn{3}{|c|}{ Female adolescents } \\
\hline & $\beta$ & $\mathrm{t}$ & Sig. & $\beta$ & $\mathrm{t}$ & Sig. \\
\hline Family (Parents and siblings) & -.37 & -6.10 & .000 & -.42 & -8.32 & .000 \\
\hline Teachers & -16 & 02.71 & .007 & -.12 & -2.45 & .015 \\
\hline Classmates & -.23 & -3.70 & .000 & -.14 & -2.83 & .005 \\
\hline Explained variance (Adjusted $\mathrm{R}^{2}$ ) & & .22 & & & .20 & \\
\hline
\end{tabular}

Table 5.

Associations between acceptance circuits and psychological states of male and female adolescents.

\begin{tabular}{|c|c|c|c|c|c|c|}
\hline \multirow{2}{*}{ Acceptance by } & \multicolumn{3}{|c|}{ Male adolescents } & \multicolumn{3}{|c|}{ Female adolescents } \\
\hline & $\beta$ & $\mathrm{t}$ & Sig. & $\beta$ & $\mathrm{t}$ & Sig. \\
\hline Father & & & & -.212 & -3.484 & .001 \\
\hline Mother & -.240 & -3.410 & .001 & -.235 & -3.902 & .000 \\
\hline Brothers & & & & -.131 & -2.124 & .034 \\
\hline Sisters & -.146 & -2.085 & .038 & & & \\
\hline \multicolumn{7}{|l|}{ Male teachers } \\
\hline Female teachers & -.140 & -2.096 & .037 & & & \\
\hline Male classmates & -.136 & -1.989 & .048 & & & \\
\hline \multicolumn{7}{|l|}{ Female classmates } \\
\hline Explained variance (Adjusted $\mathrm{R}^{2}$ ) & & 22.4 & & & 21.9 & \\
\hline
\end{tabular}

cognitive generalization in the adolescents' minds. For this, there is a need for further research that involves behavioral measures of acceptance-rejection.

All the eight circuits of perceived acceptance-rejection were associated with adolescents' psychological states: The higher the perceived acceptance, the lower the experienced psychological states. Owing to the high correlation coefficients between acceptance scores of all eight circuits, we found that these circuits merge in three major independent factors: family, teachers, and classmates. All of them were significantly associated with psychological states of male and female adolescents.

Post hoc stepwise regressions indicate that $22.4 \%$ of experienced male psychological states are explained by perceived acceptance-rejection by mother, sisters, female teachers, and male classmates, and $21.9 \%$ of experienced female psycho- 
logical states are explained by perceived acceptance-rejection by mother, father, and brothers. Experienced psychological states of male adolescents were associated with perceived acceptance-rejection circuits, mainly by female figures at home and at school, while those of female adolescents were associated with acceptance-rejection circuits at home only. Interestingly, perceived mothers' acceptance-rejection was central among male and female adolescents, while that of the fathers was associated only with female psychological states. In addition, the experienced psychological states of both male and female adolescents were not associated with perceived acceptance-rejection circuits with the same sex siblings: Psychological states of male adolescents were associated with sisters and those of female adolescents with brothers. These findings support other findings that indicated a cross-gender effect and intermediation between various circuits of acceptance-rejection (Rohner, 2010; Tulviste \& Rohner, 2010).

In this research we found robust evidence of the association between various perceived circuits of rejection and adolescents' experienced psychological states; nevertheless the relationship between rejection and psychological states is far from simple. It is advisable to perceive this relationship as a system of acceptance-rejection, where many factors interact and intermediate. The relationship with psychological states is not a self-evident cause-effect relationship. The acceptance-rejection by significant others interacts with the child's behavior in a mutual way and is also moderated by many other etiological factors, such as socialization and genetic factors.

It is important to note that some circuits of perceived acceptance-rejection that were significantly associated with experienced psychological states when treated separately as shown in table 3, turned out to be insignificant when treated together in one regression analysis (Table 5). This difference discloses the danger of studying the explained variance of experienced psychological states via single or few circuits of perceived acceptance-rejection. In such reductionist studies, the shared variances between the circuits are overlooked, and thus produce false and unreal associations between acceptance-rejection and psychological states. This situation reinforces the need for a systemic approach in research related to parenting, already highlighted in former articles by the author (Dwairy, 2009a, $2009 \mathrm{~b}$ ). Since in real life many factors interact and generate a specific phenomenon, and the associations between two factors is dependent on the presence or absence of many other related factors, the more factors are included in one analysis, the more valid are the associations found.

Two main strong points characterize this study: The major eight circuits of rejection were studied together and a unified measure of acceptance-rejection was used to avoid methodological influences on the results. The results are based on adolescents' self-reports that provide information about the adolescents' subjective experience, which is important for clinical work, however it may not be indicate what certain significant others actually did. Therefore, there is a need for additional research among various age and cultural groups, using other tools such as parents' self-reports and observation of parentchild interaction.

Looking at rejection as a system in which various circuits interact has its implications on intervention strategies. It appears that in order to help a child, counselors and therapists need to tailor a systemic intervention, covering both the family (parents and siblings) and the school (teachers and classmates). This is crucial, in particular when dealing with a male adolescent, whose psychological adjustment is associated with figures both at home and at school, and in particular with female figures such as mothers and sisters, and female teachers in addition to male classmates.

\section{Conclusions}

Acceptance-rejection circuits at home and at school are components of a system of acceptance-rejection, in which all circuits are associated and interact with each other, and as a whole are related to children's mental health in a way that is dependent on the gender of parents, siblings, teachers, and peers and the children's gender.

\section{References}

Bank, L., Patterson, G., \& Reid, J. (1996). Negative sibling interaction patterns as predictors of later adjustment problems in adolescent and young adult males. In G. Brody (Ed.). Sibling relationships: Their causes and consequences (pp. 197-229). Westport, CT: Ablex Publishing.

Brody, G. (2004). Siblings' direct and indirect contributions to child development. Current Directions in Psychological Science, 13, 124126. doi:10.1111/j.0963-7214.2004.00289.x

Buhs, E. S., Ladd, G. W., \& Herald, S. L. (2006). Peer exclusion victimization: Processes that mediate the relation between peer group rejection and children's classroom engagement and achievement. Journal of Educational Psychology, 98, 1-13. doi: $10.1037 / 0022-0663.98 .1 .1$

Chao, R. K. (1994). Beyond parental control and authoritarian parenting style: Understanding Chinese parenting through the cultural notion of training. Child Development, 65, 1111-1120. doi: $10.2307 / 1131308$

Chao, R. K. (2001). Extending research on the consequences of parenting style for Chinese Americans and European Americans. Child Development, 72, 1832-1843. doi:10.1111/1467-8624.00381

Coie, J. D., \& Kupersmidt, J. B. (1983). A behavioural analysis of emerging social status in boys' groups. Child Development, 54, 14001416. doi:10.2307/1129803

Dwairy, M. (2006). Causality and the circuit of contradictory outcomes in research. Journal of Chinese Clinical Medicine, 5, 272-282.

Dwairy, M. (2009a). Toward a systemic approach in research: On causality and mixed results. DVARIM, Oranim Academic College, Israel (In Hebrew).

Dwairy, M. (2009b). Parenting and adolescents' psychological adjustment: Toward a systemic approach in parenting research. The Open Family Studies Journal, 2, 73-81. doi: $10.2174 / 1874922400902010066$

Dwairy, M., Achoui, M., Abouserie, R., \& Farah A. (2006). Parenting styles, individuation, and mental health of Arab adolescents: A third cross-regional research study. Journal of Cross-Cultural Psychology, 37, 262-272. doi:10.1177/0022022106286924

Dwairy, M., Achoui, M., Filus, A., Rezvan nia, P., Casullo, M., \& Vohra, N. (2010). Parenting, mental health and culture: A fifth cross-cultural research on parenting and psychological adjustment of children. Journal of Child and Family Studies, 19, 36-41. doi: 10.1007/s10826-009-9340-4

Hamuda, M. A., \& Imam, I. A. (1996). The Psychological state scale for adolescents and adults. Cairo, Egypt: Dar El Fekr El Arabi (In Arabic)

Hetherington, E., \& Clingempeel, W. (1992). Coping with marital transitions: A family systems perspective. Monographs of the Society for Research in Child Development, 57, 1-242. doi:10.1111/j.1540-5834.1992.tb00300.x

Ladd, G. W. (2005). Children's peer relations and social competence: A century of progress. New Haven, Connecticut: Yale University Press.

Ladd, G. W. (2006). Peer rejection, aggressive or withdrawn behaviour, and psychological maladjustment from age 5 to 12 : An examination of four predictive models. Child Development, 77, 822-846. 
doi:10.1111/j.1467-8624.2006.00905.x

Ladd, G. W., Herald, S. L., Slutzky, C. B., \& Andrews, R. K. (2004). Preventive interventions for peer group rejection. In L. Rapp-Paglicci, C. N., Dulmus and J. S. Wodarski (Eds.), Handbook of prevention interventions for children and adolescents. New York: Wiley.

Nelson, L. J., Rubin, K, H., \& Fox, N. J. (2005). Social withdrawal, observed peer acceptance, and the development of self-perceptions in children ages 4 to 7 years. Early Childhood Research Quarterly, 20, 185-200. doi:10.1016/j.ecresq.2005.04.007

Pulakos, J. (1987). Brothers and sisters: Nature and importance of the adult bond. The Journal of Psychology, 121, 521-522. doi:10.1080/00223980.1987.9915506

Rogers, C. R. (1951). Client-centered therapy. Boston: Houghton Mifflin.

Rogers, C. R. (1961). On becoming a person. Boston: Houghton Mifflin

Rohner, R. P. (2010). Perceived teacher acceptance, parental acceptance, and adjustment, achievement, and behaviour of school-going youths internationally. Cross-Cultural Research, 40, 1-11.

Rohner, R. P., Khaleque, A., Elias, M. S., \& Sultan, S. (2010). The relationship between perceived teacher and parental acceptance, school conduct, and the psychological adjustment of Bangladeshi adolescents. Cross-Cultural Research, 44, 239-252.

Rohner, R. P., Khaleque, A, \& Cournoyer, D. E. (2005). Parental acceptance-rejection theory, methods, evidence, and implications. URL (retrieved January 27, 2005) http://vm.uconn.edu/-rohner

Rohner, R. P., \& Pettengill, S. M. (1985). Perceived parental acceptance-rejection and parental control among Korian adolescents. Child development, 56, 524-528. doi:10.2307/1129739

Rohner, R. P., Varan, A., Koberstein, N. F., \& Özyavru, N. C. (submitted). Contributions of elder siblings' versus parents' acceptance and behavioural control to psychological adjustment of younger siblings.

Tulviste, T., \& Rohner, R. P., (2010). Relationships between perceived teachers' and parental behavior and adolescent outcomes in Estonia. Cross-Cultural Research, 44, 222-238.

Waters, B. (1987). The importance of sibling relationships in separated families. Australian and New Zealand Journal of Family Therapy, 8, 13-17. 